University of South Carolina

Scholar Commons

$10-16-2000$

\title{
High Electron Mobility in AIGaN/GaN Heterostructures Grown on Bulk GaN Substrates
}

\author{
E. Frayssinet \\ W. Knap \\ P. Lorenzini \\ N. Grandjean \\ J. Massies
}

See next page for additional authors

Follow this and additional works at: https://scholarcommons.sc.edu/elct_facpub

Part of the Electrical and Electronics Commons, and the Other Electrical and Computer Engineering Commons

\section{Publication Info}

Published in Applied Physics Letters, Volume 77, Issue 16, 2000, pages 2551-2553.

(C)Applied Physics Letters 2000, American Institute of Physics (AIP).

Frayssinet, E., Knap, W., Lorenzini, P., Grandjean, N., Massies, J., Skierbiszewski, C., Suski, T., Grzegory, I., Porowski, S., Simin, G., Hu, X., Khan, M. A., Shur, M. S., Gaska, R., \& Maude, D. (16 October 2000). High Electron Mobility in AIGaN/GaN Heterostructures Grown on Bulk GaN Substrates. Applied Physics Letters, 77 (16), 2551-2553. http://dx.doi.org/10.1063/1.1318236

This Article is brought to you by the Electrical Engineering, Department of at Scholar Commons. It has been accepted for inclusion in Faculty Publications by an authorized administrator of Scholar Commons. For more information, please contact digres@mailbox.sc.edu. 


\section{Author(s)}

E. Frayssinet, W. Knap, P. Lorenzini, N. Grandjean, J. Massies, C. Skierbiszewski, T. Suski, I. Grzegory, S. Porowski, Grigory Simin, X. Hu, M. Asif Khan, M. S. Shur, R. Gaska, and D. Maude 


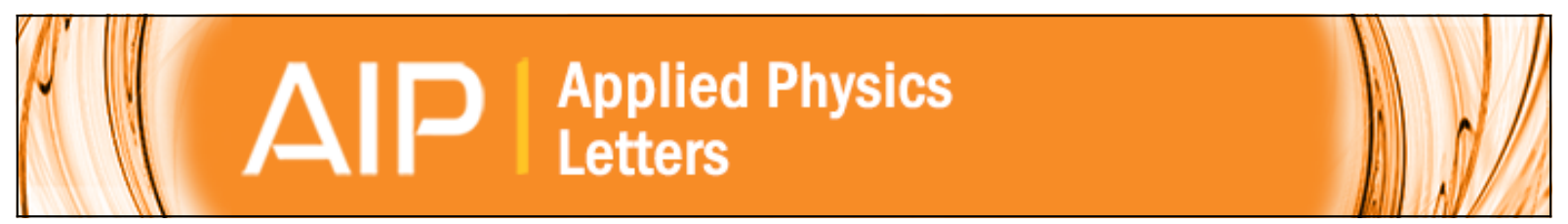

High electron mobility in AIGaN/GaN heterostructures grown on bulk GaN substrates

E. Frayssinet, W. Knap, P. Lorenzini, N. Grandjean, J. Massies, C. Skierbiszewski, T. Suski, I. Grzegory, S. Porowski, G. Simin, X. Hu, M. Asif Khan, M. S. Shur, R. Gaska, and D. Maude

Citation: Applied Physics Letters 77, 2551 (2000); doi: 10.1063/1.1318236

View online: http://dx.doi.org/10.1063/1.1318236

View Table of Contents: http://scitation.aip.org/content/aip/journal/apl/77/16?ver=pdfcov

Published by the AIP Publishing

\section{Articles you may be interested in}

Effect of dislocations on electron mobility in AIGaN/GaN and AIGaN/AIN/GaN heterostructures Appl. Phys. Lett. 101, 262102 (2012); 10.1063/1.4773510

Electron mobility exceeding $160000 \mathrm{~cm} 2 / \mathrm{V} \mathrm{s}$ in Al Ga N/Ga N heterostructures grown by molecular-beam epitaxy

Appl. Phys. Lett. 85, 5394 (2004); 10.1063/1.1824176

High mobility AIGaN/GaN heterostructures grown by plasma-assisted molecular beam epitaxy on semi-insulating GaN templates prepared by hydride vapor phase epitaxy

J. Appl. Phys. 92, 338 (2002); 10.1063/1.1484227

High electron mobility AIGaN/GaN heterostructures grown on sapphire substrates by molecular-beam epitaxy Appl. Phys. Lett. 76, 742 (2000); 10.1063/1.125880

Electron mobility exceeding $104 \mathrm{~cm} 2 / \mathrm{Vs}$ in an AIGaN-GaN heterostructure grown on a sapphire substrate Appl. Phys. Lett. 74, 3531 (1999); 10.1063/1.124151

\section{High-Voltage Amplifiers \\ - Voltage Range from $\pm 50 \mathrm{~V}$ to $\pm 60 \mathrm{kV}$ \\ - Current to 25A \\ Electrostatic Voltmeters \\ - Contacting \& Non-contacting \\ - Sensitive to $1 \mathrm{mV}$ \\ - Measure to $20 \mathrm{kV}$ \\ ENABLING RESEARCH AND \\ INNOVATION IN DIELECTRICS, \\ ELECTROSTATICS, MATERIALS, PLASMAS AND PIEZOS \\ TReK www.trekinc.com




\title{
High electron mobility in AIGaN/GaN heterostructures grown on bulk GaN substrates
}

\author{
E. Frayssinet \\ High Pressure Research Center, UNIPRESS, Polish Academy of Sciences, 01142 Warsaw, Poland \\ and G.E.S., UMR5650, CNRS-Université Montpellier 2, 34095 Montpellier, France \\ W. Knap ${ }^{\mathrm{a})}$ \\ Department of ECSE and CIEEM, Rensselaer Polytechnic Institute, Troy, New York 12180 \\ and High Pressure Research Center, UNIPRESS, P.A.S. 01142 Warsaw, Poland \\ P. Lorenzini, N. Grandjean, and J. Massies \\ CNRS-CRHEA, rue Bernard Grégory, F-06560 Valbonne-Sophia-Antipolis, France \\ C. Skierbiszewski, T. Suski, I. Grzegory, and S. Porowski \\ High Pressure Research Center, UNIPRESS, P.A.S. 01142 Warsaw, Poland \\ G. Simin, X. Hu, and M. Asif Khan \\ Department of ECE, University of South Carolina, Columbia, South Carolina 29208 \\ M. S. Shurb) and R. Gaska \\ Department of ECSE and CIEEM, Rensselaer Polytechnic Institute, Troy, New York 12180 \\ D. Maude \\ Grenoble High Magnetic Field Laboratory, CNRS-MPI, 38000 Grenoble, France
}

(Received 18 April 2000; accepted for publication 9 August 2000)

\begin{abstract}
Dislocation-free high-quality $\mathrm{AlGaN} / \mathrm{GaN}$ heterostructures have been grown by molecular-beam epitaxy on semi-insulating bulk GaN substrates. Hall measurements performed in the $300 \mathrm{~K}-50 \mathrm{mK}$ range show a low-temperature electron mobility exceeding $60000 \mathrm{~cm}^{2} / \mathrm{V}$ s for an electron sheet density of $2.4 \times 10^{12} \mathrm{~cm}^{-2}$. Magnetotransport experiments performed up to $15 \mathrm{~T}$ exhibit well-defined quantum Hall-effect features. The structures corresponding to the cyclotron and spin splitting were clearly resolved. From an analysis of the Shubnikov de Hass oscillations and the low-temperature mobility we found the quantum and transport scattering times to be 0.4 and $8.2 \mathrm{ps}$, respectively. The high ratio of the scattering to quantum relaxation time indicates that the main scattering mechanisms, at low temperatures, are due to long-range potentials, such as Coulomb potentials of ionized impurities. (C) 2000 American Institute of Physics. [S0003-6951(00)01042-1]
\end{abstract}

Since the first demonstration of the existence of a twodimensional electron gas (2DEG) at the $\mathrm{AlGaN} / \mathrm{GaN}$ interface in $1992,{ }^{1}$ tremendous progress has been realized ${ }^{2}$ in the field of $\mathrm{AlGaN} / \mathrm{GaN}$ high electron mobility transistors deposited on various substrates by different growth techniques. For example, Gaska et al. ${ }^{3}$ reached a room-temperature mobility slightly over $2000 \mathrm{~cm}^{2} / \mathrm{V} \mathrm{s}\left(n_{s}=1.3 \times 10^{12} \mathrm{~cm}^{-2}\right)$ in an $\mathrm{Al}_{0.2} \mathrm{Ga}_{0.8} \mathrm{~N} / \mathrm{GaN}$ structure deposited on $6 \mathrm{H}-\mathrm{SiC}$ substrate by low-pressure metalorganic vapor-phase epitaxy. Smorchkova et al. ${ }^{4}$ succeeded in obtaining a mobility of $51700 \mathrm{~cm}^{2} / \mathrm{V} \mathrm{s}$ at $13 \mathrm{~K}$ in $\mathrm{Al}_{0.09} \mathrm{Ga}_{0.91} \mathrm{~N} / \mathrm{GaN}$ structure grown on sapphire by rf plasma-assisted molecular-beam epitaxy (MBE), with a 2DEG density of $2.2 \times 10^{12} \mathrm{~cm}^{-2}$. In these devices, a very large lattice mismatch between the substrate and the active layer leads to a high density of threading dislocations. ${ }^{5} \mathrm{~A}$ recent theoretical study by Jena, Gossard, and Mishra ${ }^{6}$ showed that the effect of dislocations on the 2DEG mobility becomes noticeable for densities above $10^{8}-10^{10} \mathrm{~cm}^{-2}$, which correspond to the values typical for heteroepitaxial nitride layers.

a) On leave from G.E.S., UMR5650 CNRS—Université Montpellier 2, 34095 Montpellier, France.

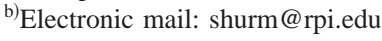

In this letter, we report on dislocation-free $\mathrm{AlGaN} / \mathrm{GaN}$ single heterostructures grown on semi-insulating $\mathrm{GaN}$ single-crystal substrates. We present the evidence of a 2DEG in such structures and characterize the 2DEG by magnetotransport experiments-low-field transport, Shubnikov de Hass, and quantum Hall effect (QHE) in magnetic fields up to $15 \mathrm{~T}$ at temperatures down to $50 \mathrm{mK}$. These measurements yield a low-temperature two-dimensional (2D) electron mobility that is one of highest ever reported for GaNbased heterojunctions. ${ }^{4}$

GaN single crystals were grown by a self-seeding process under high- $\mathrm{N}_{2}$ pressures of 10-20 kbar and at temperatures ranging from 1400 to $1700{ }^{\circ} \mathrm{C}$ from an atomic solution in Ga. Usually, such crystals are highly $n$ doped and can be made semi-insulating by adding compensating magnesium atoms to the Ga solution. The typical dimensions of the bulk crystals are $8 \times 8 \times 0.1 \mathrm{~mm}$ with the $c$ axis perpendicular to the surface. These crystals were tested to be semi-insulating with a perfect crystallographic structure. ${ }^{7}$

Prior to growth, the (0001) Ga face, which was found to be the best face polarity for a homoepitaxial layer, ${ }^{8}$ was prepared by mechanical polishing and reactive ion etching in a $\mathrm{Cl}_{2}+\mathrm{Ar}+\mathrm{CH}_{4}$ plasma. The $\mathrm{AlGaN} / \mathrm{GaN}$ single heterostructures were grown by $\mathrm{MBE}$ in a Riber system. $\mathrm{NH}_{3}$ was used 


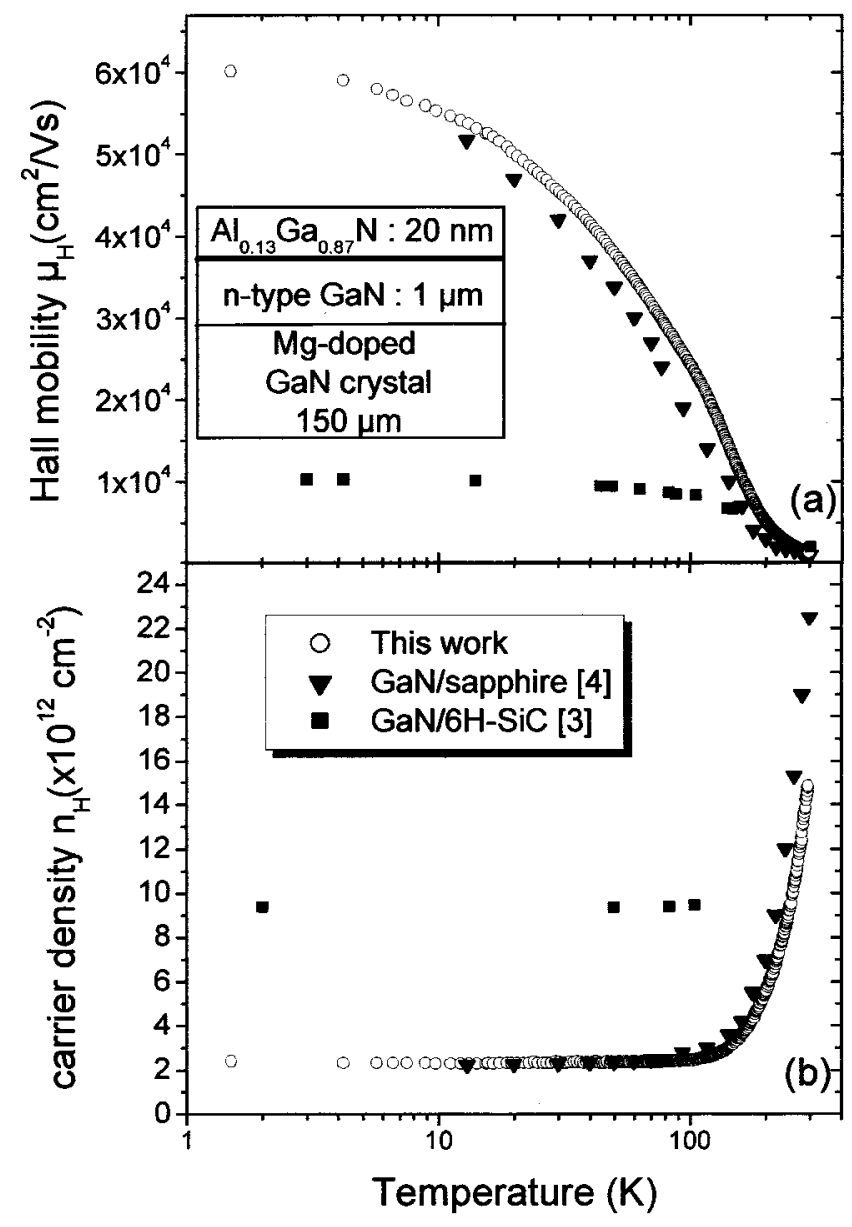

FIG. 1. Hall mobility (a) and electron sheet density (b) vs temperature for heterostructures deposited on GaN bulk substrates. The inset in (a) shows the sample structure.

as the nitrogen precursor and the group-III element were provided by standard solid-source effusion cells. An unintentionally doped GaN layer of about $1 \mu \mathrm{m}$ was grown at $800{ }^{\circ} \mathrm{C}$ on a $\mathrm{Mg}$-doped $\mathrm{GaN}$ single crystal, followed by a 200-Å-thick AlGaN layer. From photoluminescence experiments, ${ }^{9}$ the $\mathrm{Al}$ composition was estimated to be around $13 \%$. The high quality of homoepitaxial samples has already been demonstrated by the small photoluminescence linewidth (15-20 meV) measured on GaN/AlGaN quantum wells deposited using the same growth conditions. ${ }^{10}$

Figure 1 shows the Hall mobility $\mu_{H}$ [Fig. 1(a)] and the Hall carrier density $n_{H}$ [Fig. 1(b)] obtained from the lowfield-transport measurements using a lithographically defined Hall bar geometry. For the heterostructure grown on the GaN single-crystal substrate, the Hall measurements yield a $77 \mathrm{~K}$ mobility of $30000 \mathrm{~cm}^{2} / \mathrm{V} \mathrm{s}$ and a $1.5 \mathrm{~K}$ mobility of 60100 $\mathrm{cm}^{2} / \mathrm{V}$ s. For comparison, we also show in Fig. 1 the best results obtained for the heterostructures grown on sapphire by Smorchkova et $a l .{ }^{4}$ and on $6 \mathrm{H}-\mathrm{SiC}$ by Gaska et al. ${ }^{3}$ As it is seen in Fig. 1, heterostructures grown on GaN and sapphire substrates show a strong decrease of the electron concentration and an increase of carrier mobility with decreasing temperature. This effect is weakly pronounced for heterostructures with $\mathrm{SiC}$ substrates. It is worthwhile to mention that the previous two samples are characterized by a reduced dislocation density.

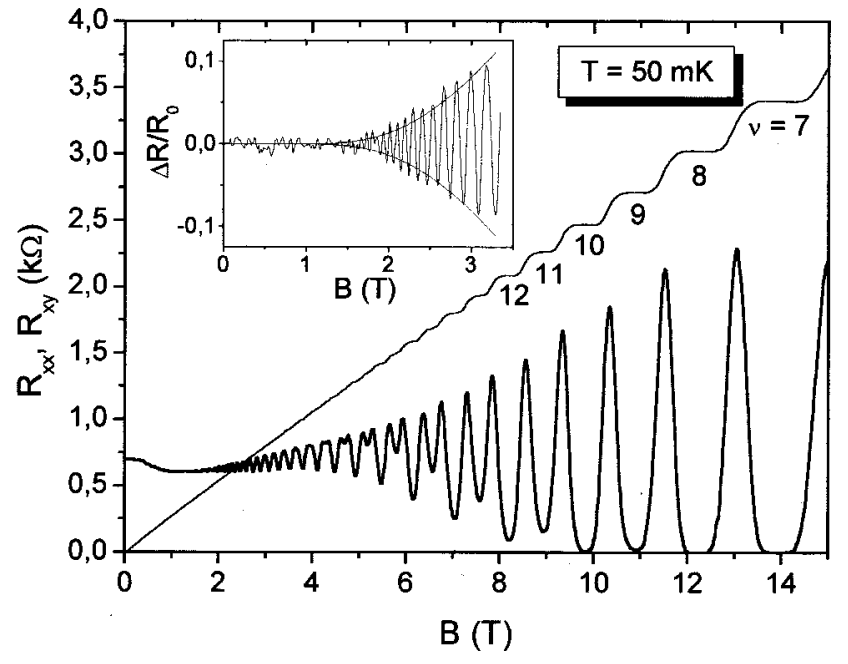

FIG. 2. Longitudinal $\left(R_{x x}\right)$ and transverse $\left(R_{x y}\right)$ magnetoresistance vs magnetic field at $50 \mathrm{mK}$. Shubnikov de Hass oscillations begin at $1.8 \mathrm{~T}$. The inset shows $\Delta R / R_{0}=\left(R_{x x}-R_{0}\right) / R_{0}$-the low-field part of $R_{x x}$ after normalization by the zero-field resistance value $R_{0}$. The best fit of the SdHOs amplitude yields the value of $T_{D}=3 \mathrm{~K}$.

We attribute the dramatic decrease of the Hall density $n_{H}$ with lowering the temperature from 300 to $100 \mathrm{~K}$, to the freeze-out of the parallel conduction in the $\mathrm{GaN}$ layer. A relatively high parallel conduction at high temperature might be related to the reduction of dislocation density. It is well known that dislocations in $\mathrm{GaN}$ act as trapping centers for free electrons. ${ }^{6}$ Therefore, for standard structures grown on sapphire or $\mathrm{SiC}$, the residual $n$-type conductivity of $\mathrm{GaN}$ layers is often reduced by the dislocations. In our case, because of the lack of dislocations, the GaN layer has an $n$-type conductivity due to the uncompensated residual donors with a density of the order of $1-2 \times 10^{17} \mathrm{~cm}^{-3}$. In the same way, the reduction of dislocation density in the template layer of the sample on the sapphire (Ref. 4) leads to visible parallel conduction effects. This conductivity freezes out at low temperatures.

The longitudinal $\left(R_{x x}\right)$ and transverse $\left(R_{x y}\right)$ magnetoresistance experiments were performed from $1.5 \mathrm{~K}$ down to 50 $\mathrm{mK}$, using the $15 \mathrm{~T}$ static magnetic field of a superconducting coil. The current through the sample was $96 \mathrm{nA}$. The results for $R_{x x}$ and $R_{x y}$ are presented in Fig. 2. The Shubnikov de Hass oscillations (SdHOs) are correlated with the well-defined QHE plateaus confirming the presence of a 2DEG at the $\mathrm{AlGaN} / \mathrm{GaN}$ interface. It is worth mentioning that the SdHOs start at low magnetic field (about 1.8 T). We also note that a second period of oscillations, due to the spin splitting, is clearly resolved. ${ }^{11}$ From the period of the SdHOs, we extract the carrier sheet density to be about 2.4 $\times 10^{12} \mathrm{~cm}^{-2}$, which is in good agreement with the low-field Hall measurements (see Fig. 1). This shows that the parallel conduction is eliminated at low temperatures, probably due to the freeze-out of the electrons on donors in the GaN channel. The absence of a positive background superimposed on the SdHOs also shows that parallel conduction is negligible at low temperatures. ${ }^{12}$ The inset in Fig. 2 shows the low-field part of the SdHOs after normalization by the low-field resistance value $R_{0}$. The magnetic-field dependence of the SdHOs amplitude $\gamma_{0}$ is described by the standard formula ${ }^{1,13}$ 


$$
\Delta R / R_{0}=\frac{4 A}{\sinh A} \exp \left(\frac{A T_{D}}{T}\right),
$$

where $A=2 \pi^{2} k_{B} T / \Delta E, T_{D}=\hbar / 2 \pi k_{B} \tau_{q}$ is the Dingle temperature determined by the quantum scattering time $\tau_{q}$ and $\Delta E=\hbar \omega_{c}$ is equal to the cyclotron resonance energy $\left(\omega_{c}\right.$ $\left.=e B / m^{*}\right)$, which depends on the effective $2 \mathrm{D}$ electron mass $m^{*}=0.240 \times m_{0}$ (Ref. 14) and on the magnetic field $B$. From the fit of the SdHOs, we obtained $\tau_{D}=0.4 \mathrm{ps}$. This time corresponds to the average time between the scattering event and is 20 times shorter than the transport scattering time $\tau_{\text {tr }}$ $=\mu m^{*} / e=8.2 \mathrm{ps}$, which is the average time between scattering events that efficiently changes the carrier momentum direction. This indicates that at low temperatures the main scattering mechanisms are due to long-range potentials such as Coulomb potentials of (i) ionized impurities in the GaN layer and/or (ii) remote scattering by impurities in the AlGaN barrier. Therefore, we believe that a further improvement of mobility in homoepitaxial structures can be achieved mainly by lowering the residual doping in the GaN layer and in the $\mathrm{AlGaN}$ barrier.

The comparison of the homoepitaxial sample of this work and the sample of Ref. 4, grown on a sapphire substrate, allows us to comment on the role of dislocations in the low-temperature mobility of 2DEG. Although the structure investigated in this work is dislocation-free, its lowtemperature mobility is only slightly higher than that of the structure grown on sapphire, which has a dislocation density of $10^{8} \mathrm{~cm}^{-2}$. Both samples also have similar carrier densities (about $2 \times 10^{12} \mathrm{~cm}^{-2}$ ). From these results, we can then draw the conclusion that for a $2 D E G$ with a density of about 2 $\times 10^{12} \mathrm{~cm}^{-2}$, a dislocation density of $10^{8} \mathrm{~cm}^{-2}$ or less does not influence the 2DEG carrier mobility. This result has been confirmed by the calculations of Jena, Gossard, and Mishra, ${ }^{6}$ who showed that the mobility limit imposed on a 2DEG, with a carrier density of $2 \times 10^{12} \mathrm{~cm}^{-2}$ and a dislocation density of $10^{8} \mathrm{~cm}^{-2}$, is around $200000 \mathrm{~cm}^{2} / \mathrm{V} \mathrm{s}$. This relative insensitivity of mobility to dislocation scattering can be explained by the strong screening effect of carriers in a 2DEG. ${ }^{6,15}$ However, as the calculations of Jena, Gossard, and Mishra clearly show, the ultimate limit for the low-field mobility at cryogenic temperatures is affected by the dislocation density, and we expect that with a further reduction of ionized impurity concentration, dislocation-free samples will exhibit much higher mobility values.

In conclusion, high-quality $\mathrm{AlGaN} / \mathrm{GaN}$ heterostructures have been grown by MBE on Mg-doped GaN single crystals. The presence of the 2DEG at the interface has been proved by the observation of the Shubnikov de Hass oscillations and by the well-defined quantum Hall-effect plateaus. The lowtemperature mobility $\left(60100 \mathrm{~cm}^{2} / \mathrm{V} \mathrm{s}\right.$ at $\left.1.5 \mathrm{~K}\right)$ has been measured. Our results show that the homoepitaxial growth on GaN bulk substrates allows us to obtain high-quality GaN-based heterostructures for which the main scattering mechanisms are due to the long-range potentials such as Coulomb potentials of ionized impurities in the GaN layer and/or in the $\mathrm{AlGaN}$ barrier.

${ }^{1}$ M. Asif Khan, J. N. Kuznia, J. M. Van Hove, N. Pan, and J. Carter, Appl. Phys. Lett. 60, 3027 (1992).

${ }^{2}$ O. Ambacher, J. Smart, J. R. Shealy, N. G. Weimann, K. Chu, M. Murphy, W. J. Schaff, L. F. Eastman, R. Dimitrov, L. Wittmer, M. Stutzmann, W. Rieger, and J. Hilsenbeck, J. Appl. Phys. 85, 3222 (1999).

${ }^{3}$ R. Gaska, J. W. Wang, A. Osinsky, Q. Chen, M. Asif Khan, A. O. Orlov, G. L. Snider, and M. S. Shur, Appl. Phys. Lett. 72, 707 (1998).

${ }^{4}$ I. P. Smorchkova, C. R. Elsass, J. P. Ibbetson, R. Vetury, B. Heying, P. Fini, E. Haus, S. P. DenBaars, J. S. Speck, and U. K. Mishra, J. Appl. Phys. 86, 4520 (1999).

${ }^{5}$ C. Youtsey, L. T. Romano, R. J. Molnar, and I. Adesida, Appl. Phys. Lett. 73, 3537 (1999).

${ }^{6}$ D. Jena, A. C. Gossard, and U. K. Mishra, Appl. Phys. Lett. 76, 1707 (2000).

${ }^{7}$ S. Porowski, MRS Internet J. Nitride Semicond. Res. 4S1, G1.3 (1999).

${ }^{8}$ M. Leszczynski, B. Beaumont, E. Frayssinet, W. Knap, P. Prystawko, T. Suski, I. Grzegory, and S. Porowski, Appl. Phys. Lett. 75, 1 (1999).

${ }^{9}$ G. Steude, T. Christmann, B. K. Meyer, A. Goeldner, A. Hoffmann, F. Bertram, J. Christen, H. Amano, and I. Akasaki, MRS Internet J. Nitride Semicond. Res. 4S1, G3.26 (1999).

${ }^{10}$ N. Grandjean, B. Damilano, S. Dalmasso, M. Leroux, M. Laügt, and J. Massies, J. Appl. Phys. 86, 3714 (1999).

${ }^{11}$ W. Knap, E. Frayssinet, M. L. Sadowski., C. Skierbiszewski, D. Maude, V. Falko, M. Asif Khan, and M. Shur, Appl. Phys. Lett. 75, 3156 (1999).

${ }^{12}$ S. Contreras, W. Knap, E. Frayssinet, M. L. Sadowski, M. Goiran, and M. Shur, J. Appl. Phys. (submitted).

${ }^{13}$ P. T. Coldridge, Phys. Rev. B 44, 3793 (1991).

${ }^{14}$ W. Knap, S. Contreras, H. Alause, C. Skierbiszewski, J. Camassel, M. Dyakonov, J. L. Robert, J. Yang, Q. Chen, M. Asif Khan, M. L. Sadowski, S. Huant, F. H. Yang, M. Goiran, J. Leotin, and M. S. Shur, Appl. Phys. Lett. 70, 2123 (1997).

${ }^{15}$ M. S. Shur, B. Belmont, and M. A. Khan, J. Electron. Mater. 25, 777 (1996). 